\title{
Morphological and Molecular Identification of Filamentous Fungi Isolated from Cosmetic Powders
}

\author{
Flavia Cristina Jastale Pinto ${ }^{1}$, Daniel Braga de Lima ${ }^{1}$, Bruna Carla Agustini ${ }^{1}$, Cibelle \\ Borba Dallagassa $^{2}$, Maria Fernanda Shimabukuro ${ }^{1}$, Márcio Chimelli ${ }^{1}$, Debora Brand ${ }^{1}$, \\ Cyntia Maria Telles Fadel-Picheth ${ }^{2}$ and Tania Maria Bordin Bonfim ${ }^{1 *}$ \\ ${ }^{1}$ Laboratório de Enzimologia e Tecnologia das Fermentações; Universidade Federal do Paraná; Av. Pref. Lothário \\ Meissner, 632; 80210-170; Curitiba - PR - Brasil. ${ }^{2}$ Laboratório de Bacteriologia Clínica; Universidade Federal do \\ Paraná; Av. Pref. Lothário Meissner, 632; 80210-170; Curitiba - PR - Brasil.
}

\begin{abstract}
Seven fungi were isolated from 50 samples of cosmetic powders. Morphological analyses and ribosomal DNA Internal Transcribed Spacers sequencing were performed which allowed the discrimination of the isolated fungi as Aspergillus fumigatus, Penicillium sp., and Cladosporium sp. which could have, among their species, potentially pathogenic microorganisms.
\end{abstract}

Key words: Microbial contamination, ribosomal DNA, cosmetics

\section{INTRODUCTION}

Cosmetics market requires constant product releases to ensure the company's competitiveness. New trends and consumer needs require agility in developing the new products with quality. Products, such as cosmetic and some food, are not expected to be sterile, however, they must be free of microbial pathogens and the total number of aerobic microorganisms per gram must be low (Behravan et al. 2005). The contamination of these products can result in their conversion into products hazardous for the consumers (Brasil 1999, Orus and Leranoz 2005, Sousa 2008). These contaminations could spoil the formulas in manufacturing plants and consumer's homes at ambient temperatures, if satisfactory measures of preservation are not instituted (Brasil 1999). Studies have reported the development and validation of rapid detection of microbial contamination in the cosmetic and pharmaceutical formulations (Mislivec et al. 1993, Tran and Hitchins 1994, Anelich and Korsten 1996, Álvarez-Lerma et al. 2008, Lundov and Zachariae 2008). Fungi identification and classification lie on the traditional analyses of macroscopic and microscopic structures (Larone 2002, Watanabe 2002), and their characteristics may change considerably depending on the environment and the conditions they are exposed to. Therefore, molecular methods are tools that help to differentiate the microorganisms (Jimenez et al. 1999, Mirhosseini et al. 2011). Ribosomal DNA (rDNA) is an interesting target to fungal phylogeny studies as it encodes the highly polymorphic 600-800 bp ITS region (Internal Transcribed Spacers), being used for the differentiation of many yeast and fungal species (Larena et al. 1999, Anderson and Cairney 2004, Pinheiro 2004, Anderson and Parkin 2007).

*Author for correspondence: tbonfim@ufpr.br 
Because of the growing market of Brazilian cosmetics, the concern about product quality and consumer safety has increased in the recent years. This study aimed to detect the contamination and to characterize the filamentous fungi present in the cosmetic powders commercialized in Southern Brazil.

\section{MATERIAL AND METHODS}

\section{Samples}

Fifty Brazilian cosmetic powders from three brands (A, B, and $\mathrm{C}$ ) were purchased.

\section{Isolation and Morphological Identification}

For the microorganism isolation, the cosmetic powders were diluted in Nutrient Broth (peptone 5 g. $1^{-1}$; beef extract $\left.3 \mathrm{~g}^{-1} \mathrm{l}^{-1}\right)$, plated in Sabouraud Dextrose Agar (peptone 10 g. $1^{-1}$; glucose 40 g..$^{-1}$; agar $15 \mathrm{~g}^{-1} \mathrm{l}^{-1}$ ) and incubated at $26^{\circ} \mathrm{C}$ for five days. The grown colonies were transferred to Malt extract agar slants (malt extract $30 \mathrm{~g} . \mathrm{l}^{-1}$; peptone 3 g. $1^{-1}$; agar 15 g. $1^{-1}$ ) and incubated at $26^{\circ} \mathrm{C}$ for five days. For the macroscopic analysis, the colonies were observed daily for color, size, texture, and exudates formation. Reproductive structures were microscopically observed by the microcultivation technique in malt extract agar, which was adapted from the Brazilian National Health Surveillance Agency (ANVISA) methodology.

\section{DNA Extraction and PCR amplification}

Fungi were cultivated in the flasks containing malt extract broth, at $26^{\circ} \mathrm{C}$ and $170 \mathrm{rpm}$. The pellets were washed with TE Buffer (1 M Tris-Cl, $0.5 \mathrm{M}$ EDTA pH 8.0), added of $500 \mu \mathrm{l}$ of lysis buffer and $10 \mu \mathrm{l}$ of SDS $10 \%$ and maintained for 10 minutes at room temperature and then at $60{ }^{\circ} \mathrm{C}$ for 10 minutes. Glass beads and $250 \mu \mathrm{l}$ of phenol: chloroform: isoamyl alcohol (25:24:1) were added to the pellets, homogenized and centrifuged at $13000 \times \mathrm{g}$. One milliliter of ethanol was added to the supernatant and centrifuged. One milliliter of $80 \%$ ethanol was added to the precipitate and homogenized with subsequent centrifugation $(13000 \times \mathrm{x})$. Ethanol was completely dried at $40{ }^{\circ} \mathrm{C}$; the extracted DNA was resuspended in $30 \mu \mathrm{l}$ of deionized water and stored at $4{ }^{\circ} \mathrm{C}$ until use (Guimarães et al. 2006). All the solutions used were as described by Xufre et al. (2000). The PCR reactions were carried out in $25 \mu \mathrm{l}$ volume using 4 to $10 \mu \mathrm{l}$ of the template DNA and ITS1-F (5' CTT GGT CAT TTA GAG GAA GTA A 3') and ITS-4 (5' TCC TCC GCT TAT TGA TAT GC 3') primers (Anderson and Cairney 2004). The thermocycler programme used was an initial denaturation $\left(94^{\circ} \mathrm{C}\right.$ for $\left.4 \mathrm{~min}\right), 30$ cycles of denaturation $\left(94^{\circ} \mathrm{C}\right.$ for $\left.1 \mathrm{~min}\right)$, annealing $\left(40{ }^{\circ} \mathrm{C}\right.$ increasing $0.5{ }^{\circ} \mathrm{C}$ per second during $\left.30 \mathrm{~s}\right)$, and extension $\left(72{ }^{\circ} \mathrm{C}\right.$ for $1 \mathrm{~min}$ ) (Anderson and Cairney 2004). The genetic materials were electrophoresed on $1 \%$ agarose gel in the TAE buffer $1 \mathrm{x}$ (40 mM Tris acetate; $1 \mathrm{mM}$ EDTA), and gels were stained with ethidium bromide and observed in UV detector (Sambrook et al. 1989). Approximated molecular sizes of the amplicons were determined using molecular weight marker $1 \mathrm{~Kb}$ Plus DNA Ladder (Invitrogen, Carlsbad, California, USA).

\section{DNA sequencing and data analysis}

Amplicons were sequenced using the DYEnamic ET Dye Terminator Cycle Sequencing kit (GE Healthcare Life Sciences - Buckinghamshire, UK) and the automatic DNA sequencer ABI Prism 377 (Applied Biosystems, Brazil). The rDNA amplicons were sequenced twice, aligned using the BioEdit Sequence Alignment Editor to obtain the consensus sequence, and compared through the CLUSTALW

(http://www.ebi.ac.uk./tools/clustalw/) (Hall 1999). Blastn searches were performed at the NCBI GenBank data library (http://blast.ncbi.nlm.nih.gov/Blast.cgi) (Altschul et al. 1997) and compared between themselves using the CLUSTALW (http://ebi.ac.uk/tools/clustalw/). The sequence data were deposited in the GenBank Nucleotide Database.

\section{RESULTS AND DISCUSSION}

Seven filamentous fungi were isolated from the cosmetic powders but none developed exudate. Filamentous fungi 5, 9, 11, 12 and 13 showed green colonies of cotton appearance. The filamentous fungus 4 differed from the others in color; the filamentous fungus 10 differed in appearance presenting brown colored colonies and powder aspect (Fig. 1). 


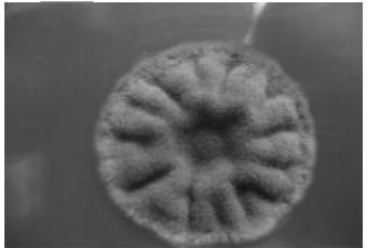

A

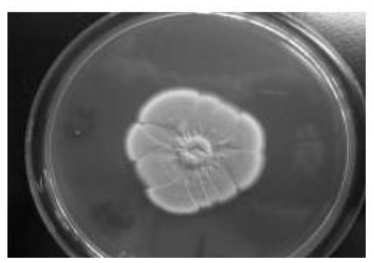

E

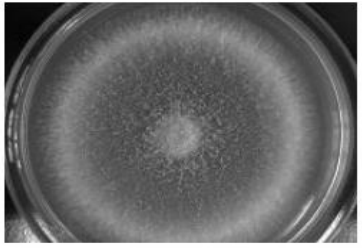

B



$\mathrm{F}$

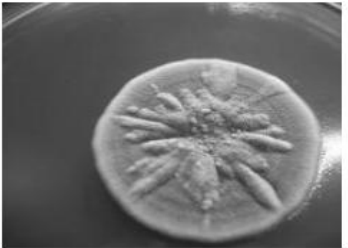

C

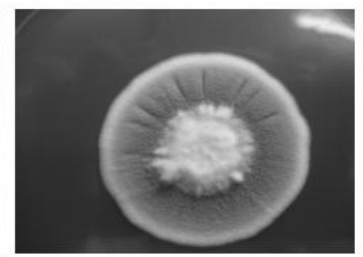

G

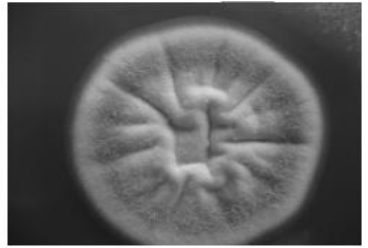

D

Figure 1 - Filamentous fungi growth in Malt extract agar. $10^{6}$ spores of each filamentous fungus were incubated for five days at $26^{\circ} \mathrm{C} \pm 2{ }^{\circ} \mathrm{C}$. A: Filamentous fungus $4-$ Cladosporium sp.; B: Filamentous fungus 10 - Aspergillus fumigatus; C: Filamentous fungus 5 Penicillium sp.; D: Filamentous fungus 9 - Penicillium sp.; E: Filamentous fungus 11 Penicillium sp.; F: Filamentous fungus 12 - Penicillium sp.; G: Filamentous fungus 13 - Penicillium sp.

The observation of reproductive structures by the optical microscopy confirmed that the filamentous fungi $5,9,11,12$ and 13 presented different reproductive structures from filamentous fungi 4 and 10 (Fig. 2). The combined analysis showed that the filamentous fungi 5, 9, 11, 12 and 13 were Penicillium sp., filamentous fungus 4 was Cladosporium sp. and filamentous fungus 10 was Aspergillus sp.. The ITS amplicons ranging from 650 to $700 \mathrm{bp}$ were in agreement with the other

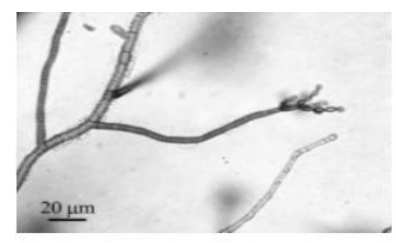

A

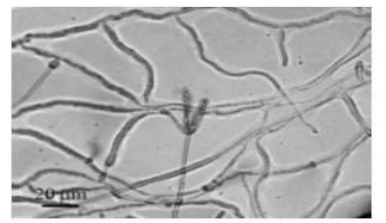

E

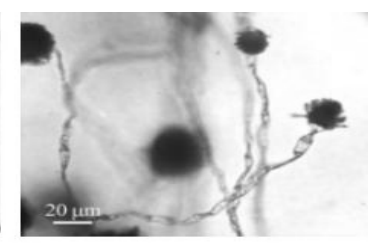

B

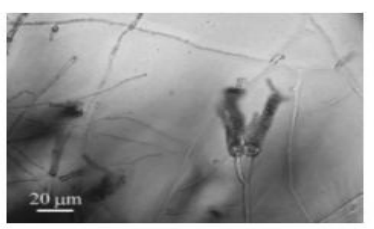

F reports (Larena et al. 1999, Anderson and Parkin 2007, Cardoso et al. 2007, Manter and Vivanco 2007). The GenBank accession numbers are indicated in the brackets. The filamentous fungus 4 was identified as Cladosporium sp. (GU270579), filamentous fungi $5,9,11,12$ and 13 were identified as Penicillium sp. (GU270574, GU270576, GU270575, GU270577 and GU270578) and filamentous fungus 10 was identified as Aspergillus fumigatus (GQ499183).

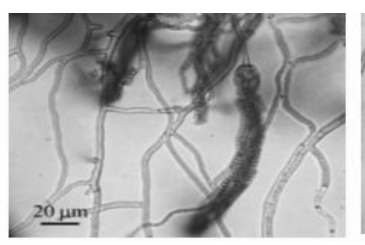

C

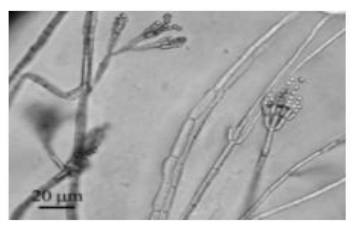

G

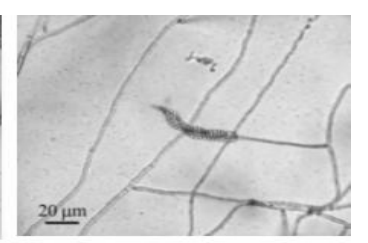

D

Figure 2 - Development of reproductive structures in Malt Extract agar. Microscopical analyses were performed after incubation for five days at $26{ }^{\circ} \mathrm{C} \pm 2{ }^{\circ} \mathrm{C}$. A: Filamentous fungus 4 - Cladosporium sp.; B: Filamentous fungus 10 - Aspergillus fumigatus; C: Filamentous fungus 5 - Penicillium sp.; D: Filamentous fungus 9 - Penicillium sp.; E: Filamentous fungus 11 - Penicillium sp.; F: Filamentous fungus 12 - Penicillium sp.; G: Filamentous fungus 13 - Penicillium sp. 
There was high similarity between the ITS sequences of the filamentous fungi identified as Penicillium sp., with the filamentous fungus 13 showing the lowest percentage of similarity among the other Penicillium sp. (87 to 89\%).

The taxonomy of Penicillium is complex due to its large number of species which have very few differences. Despite that the classification systems of organisms are based on the observable characteristics, many species classified as Penicillium are morphologically similar, and this method of identification remains difficult (Cardoso et al. 2007). This was observed in the present results, since the morphological analyses showed all the isolated fungi belonging to Penicillium genus with green colonies of cotton appearance. The comparison of nucleotide sequence of ITS region between these fungi also did not reveal a satisfactory discrimination since there was very low degree of ITS variability, as previously reported by Cardoso et al. (2007).

Therefore, seven filamentous fungi isolated from cosmetics powders and identified them as Aspergillus fumigatus, Penicillium sp., and Cladosporium sp. could have among their species potentially pathogenic microorganisms (Behravan et al. 2005, Orus and Leranoz 2005). These results are valuable due to the fact that the use of contaminated cosmetic products, even within the limits established by the Brazilian legislation, could cause serious damage to the health especially in the people who already have poor health condition.

\section{ACKNOWLEDGEMENTS}

The authors would like to thank Coordenação de Aperfeiçoamento de Pessoal de Nível Superior (CAPES) for financial support.

\section{REFERENCES}

Behravan J, Bazzaz BSF, Malaekeh P. Survey of bacteriological contamination cosmetics creams in Iran (2000). Int J Dermatol. 2005; 44: 482-485.

Brasil. RDC n 481, de 23 de setembro de 1999. Estabelece os parâmetros de controle microbiológico para os produtos de higiene pessoal, cosméticos e perfumes conforme o anexo desta resolução.: ANVISA (National Health Surveillance Agency); 1999.
Orus P, Leranoz S. Current trends in cosmetic microbiology. Int Microbiol. 2005; 8: 77-79.

Sousa CP. The Impact of Food Manufacturing Practices on Food borne Diseases. Brazilian Archieves of Biology and Technology. 2008; 51(4): 815-823.

Mislivec PB, Bandler R, Allen G. Incidence of fungi in shared-used cosmetics available to the public. $J$ AOAC Int. 1993; 2: 430-436.

Tran TT, Hitchins AD. Microbial survey of shared-use cosmetic test kits available to the public. J Ind Microbiol. 1994; 13(6): 389-391.

Anelich LE, Korsten L. Survey of microorganisms associated with spoilage of cosmetic creams manufactured in South Africa. Int J Cosmet Sci. 1996; 18: 25-40.

Álvarez-Lerma F, Maull E, Terradas R, Segura C, Planells I, Coll P, et al. Moisturizing body milk as a reservoir of Burkholderia cepacia: outbreak of nosocomial infection in a multidisciplinary intensive care unit. Crit Care. 2008; 12: 1-6.

Lundov MD, Zachariae C. Recalls of microbiologically contaminated cosmetics in EU from 2006 to May 2008. Int J Cosmet Sci. 2008; 30: 471-474.

Larone DH. Medically important fungi - A guide to identification. $4^{\text {th }}$ ed. Washington: Americam Society for Microbiology Press; 2002.

Watanabe T. Pictorial atlas of soil and seed fungi morphologies of cultured fungi and key to species. $2^{\text {nd }}$ ed. Boca Ratón: CRC Press; 2002.

Jimenez L, Bosko Y, Smalls S, Ignar R, English D. Molecular detection and identification of Aspergillus niger contamination in cosmetic pharmaceutical raw materials and finished products. J Rapid Meth Autom Microbiol. 1999; 7(1): 39-46.

Mirhosseini SZ, Seidavi A, Shivazad M, Chamani M, Sadeghi AA, Pourseify R. Detection of Clostridium sp. and its Relation to Different Ages and Gastrointestinal Segments as Measured by Molecular Analysis of 16S rRNA Genes. Braz. Arch. Biol. Technol. 2011; 53(1): 69-76.

Larena I, Salazar O, Gonzalez V, Julian MC, Rubio V. Design of a primer for ribosomal DNA internal transcribed spacer with enhanced specificity for ascomycetes. J Biotechnol. 1999; 75: 187-194.

Anderson IC, Cairney WG. Diversity and ecology of soil fungal communities: increased understanding through the application of molecular techniques. Environ Microbiol. 2004; 6: 769-779.

Pinheiro M. Estudo de variabilidade genética de Aspergillus flavus como base para o desenvolvimento de PCR multiplex para a detecção de fungos produtores de aflotoxinas em castanha-do-brasil e castanha-de-caju [M.Sc. Dissertation]. Brasília, Brasil: Universidade Católica de Brasília; 2004. 
Anderson IC, Parkin PI. Detection of active soil fungi by RT-PCR amplification of precursor rRNA molecules. J Microbiol Methods. 2007; 68(2): 248253.

Guimarães TM, Moriel DG, Machado IMP, FadelPicheth CMT, Bonfim TMB. Isolation and characterization of Saccharomyces cerevisiae strains of winery interest. Braz J Pharm Sci. 2006; 42(1): 119-126.

Xufre A, Simões F, Gírio F, Clemente A, AmaralCollaço MT. Use of RAPD analysis for differentiation among six enological Saccharomyces spp. strains. Food Technol Biotechnol. 2000; 30: 5358.

Sambrook J, Fritsch EF, Maniatis T. Molecular cloning - a laboaratory manual. $2^{\text {nd }}$ ed. New York: CSH; 1989.

Hall TA. BioEdit: a user-friendly biological sequence alignment editor and analysis program for Windows 95/98/NT. Nucleic Acids Symp Ser. 1999; 41: 95-98.
Altschul SF, Madden TL, Schaffer AA, Zhang J, Zhang Z, Miller W, et al. Gapped BLAST and PSI-BLAST: a new generation of protein database search programs. Nucleic Acids Res. 1997; 25(17): 33893402.

Cardoso PG, Queiroz MV, Pereira OL, Araújo EF. Morphological and molecular diferentiation of the pectinase producing fungi Penicillium expansum and Penicillium griseoroseum. Braz J Microbiol. 2007; 38: 71-77.

Manter DK, Vivanco JM. Use of the ITS primers, ITS1F and ITS4, to characterize fungal abundance and diversity in mixed-templates samples by qPC and length heterogeneity analysis. J Microbiol Methods. 2007; 71: 7-14.

Received: June 21, 2011; Revised: December 19, 2011; Accepted: May 15, 2012. 
PÁGINA EM

BRANCO 